\title{
The biomechanics of uterine prolapse impact rectal intussusception, ODS and surgical restoration
}

\author{
P. E. P. Petros ${ }^{1}$ (1)
}

Received: 27 January 2022 / Accepted: 27 January 2022 / Published online: 1 February 2022

c) Springer Nature Switzerland AG 2022

Prior to commencement of labor, the collagen of connective tissue in the birth canal depolymerizes and loses $95 \%$ of its strength [1]. Depolymerization plasticizes all connective tissues, so it can stretch, but does not rupture. The biomechanics of uterine prolapse commence at the entry to the birth canal. At $10 \mathrm{~cm}$ dilatation of the cervix, the cardinal (CL) ligaments may stretch to cause a cystocele and further down, a recto-peri-neocele; the uterosacral ligaments (USLs), may lengthen to cause uterine prolapse (Fig. 1). The USLs are attached to the lateral wall of the rectum by filamentous ligament-like structures. Extreme USL damage may cause the USLs to lengthen considerably, resulting in 3rd- or 4thdegree uterine prolapse. When the uterus descends, the USLs lengthen and invariably splay laterally, to create an enterocele. Lateral displacements of USLs carry the lateral rectal wall with them (Fig. 1). Consequently, the anterior rectal wall stretches laterally, widening it, so it prolapses inwards to cause intussusception, (Fig. 1). Such anatomical distortion would naturally alter the morphological and biomechanical properties of the anterior rectal wall.

Uniaxial tensile tests on the rectum in patients with obstructed defecation syndrome (ODS) showed that the tangential modulus of elasticity was significantly higher in the control group than in the ODS group [2]. Histology showed statistically less collagen in the rectal wall in the ODS group [2], findings confirmed by other authors [3]. The normal colorectum has in-plane tissue anisotropy, indicating higher stiffness in the longitudinal direction than in the circumferential direction [4]. Weaker lateral rectal walls support the hypothesis of elongated, laterally splayed USLs as a prime pathogenic factor in ODS.

\footnotetext{
P. E. P. Petros

pp@kvinno.com

https://www.integraltheory.org/

1 University of Western Australia School of Mechanical and Mathematical Engineering, Perth, WA, Australia
}

If this is the pathogenic mechanism, a rectopexy mesh placed on a weakened anterior wall of the rectum, does not address causation of the intussusception. Rather, the USLs themselves should be shortened and strengthened. This is best done vaginally, with a USLs sling, which not only shortens the USLs, the polypropylene tape which is used creates new collagen to strengthen the USLs.

This methodology was applied by Abendstein et al. [5], who used a posterior intravaginal slingplasty (PIVS) operation to reinforce USLs in 48 women with various degrees of vaginal vault descensus, clinical rectoceles and defecatory dysfunction. PIVS uses a curved tunneler $30 \mathrm{~cm}$ long inserted via the perineum to penetrate the sacrospinous ligament (SSL) bilaterally. A $1 \mathrm{~cm}$ wide tape attached to the apex is pulled back through the tunneler, exiting at the perineum. The tape creates a strong neo-ligamentous attachment of apex to SSL.

In addition to PIVS, they reconstructed the rectovaginal fascia and perineal body. Complete normalization of defecation was reported by 45 patients $(94 \%)$ at both visits after surgery. Of the 27 patients with fecal incontinence, 18 (66\%) reported cure, $5(19 \%)>50 \%$ improvement, and 4 no change. Postoperative proctograms showed resolution of the rectal intussusception in $89 \%$. The authors concluded, "connective tissue damage to the rectal wall supports may cause it to sag inwards, "intussusception". The posterior sling creates a foreign body reaction which reinforces the damaged uterosacral ligament and "reglues" the ligament's attachments to levator plate, cervical ring and rectovaginal fascia to suspend and stretch the rectal wall."

Anatomy is anatomy. The same result obtained by Abendsetin et al. [5] could be achieved laparoscopically. The USLs could be plicated and shortened using a collagenotrophic $2 \mathrm{~mm}$ tape or even a $0.8 \mathrm{~mm}$ No5 polyester suture.

As USL repair is in the correct anatomical plane, it largely avoids reported anorectal dysfunction complications from sacrocolpopexy where a large mesh is attached to the sacral promontory, which is far away from the insertion 

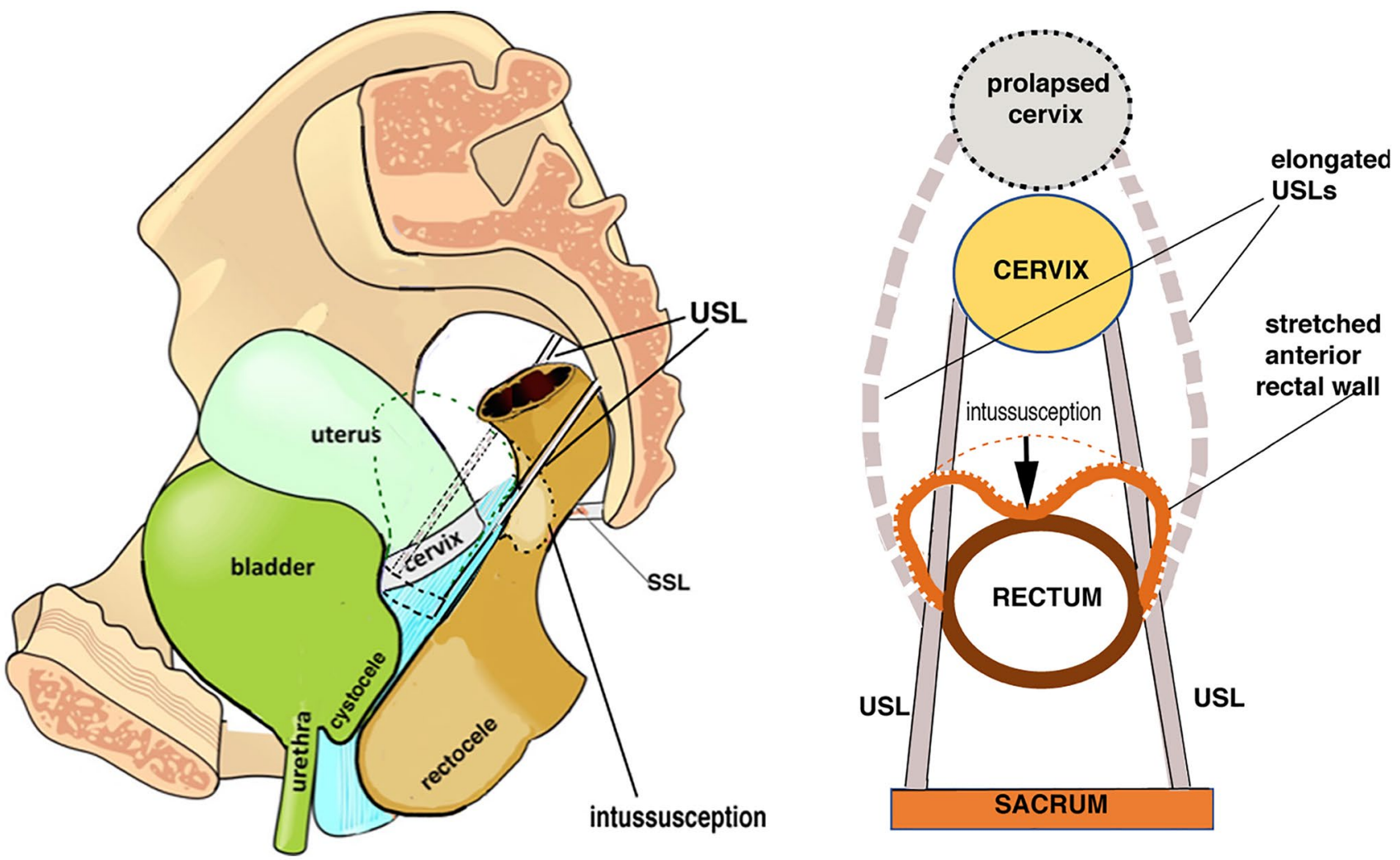

Fig. 1 Uterine prolapse caused by damage during childbirth and elongation of the uterosacral ligaments (USL). SSL sacrospinous ligament. Right figure: attachment of USLs to the lateral wall of rectum drag the more distensile lateral wall with them as they splay laterally

points of USL, S2-4 pre-sacral fascia. An excessively tight sacrocolpopexy may counteract the force of the downward opening vector, to cause urinary and fecal retention [6]. The problem of mesh complications, mainly erosions, remains with both approaches, vaginal and laparoscopic.

\section{Funding None.}

\section{Declarations}

Conflict of interest The author declares no conflict of interest.

Ethical approval Not applicable.

Informed consent Not applicable.

\section{References}

1. Rechberger T, Uldbjerg N, Oxlund H (1988) Connective tissue changes in the cervix during normal pregnancy and pregnancy complicated by a cervical incompetence. Obstets Gynecol. $71: 563-567$ as they lengthen. The anterior rectal wall elongates laterally, weakening it structurally. Its collagen concentration lessens and the anterior rectal wall invaginates to cause intussusception

2. Brunenieks I, Pekarska K, Kasyanov V, Groma V (2017) Biomechanical and morphological peculiarities of the rectum in patients with obstructed defecation syndrome. Rom J Morphol Embryol 58(4):1193-1200 (PMID: 29556608)

3. Ren XH, Yaseen SM, Cao YL, Liu WC, Shrestha S, Ding Z, Wu YH, Zheng KY, Qian Q, Jiang CQ (2016) A transanal procedure using TST STARR plus for the treatment of obstructed defecation syndrome: 'A mid-term study.' Int J Surg 32:58-64. https://doi. org/10.1016/j.ijsu.2016.06.039

4. Siri S, Zhao Y, Maier F, Pierce DM, Feng B (2020) The macroand micro-mechanics of the colon and rectum I: experimental evidence saeed. Bioengineering. https://doi.org/10.3390/bioen gineering 7040130

5. Abendstein B, Brugger BA, Furtschegger A, Rieger M, Petros PE (2008) Role of the uterosacral ligaments in the causation of rectal intussusception, abnormal bowel emptying, and fecal incontinence-a prospective study. Pelviperineology 27:118-121

6. Petros PEP, Swash M (2011) Sacrocolpopexy may cause difficult defecation by inhibiting the external opening out mechanism. Int Urogyn J 22(2):255-255 201. https://doi.org/10.1007/ s00192-010-1292-0

Publisher's Note Springer Nature remains neutral with regard to jurisdictional claims in published maps and institutional affiliations. 